\title{
Multi-fractal characteristics of pore structure for coal during the refined upgrading degassing temperatures
}

\author{
Jianjun Wang ${ }^{1} \cdot$ Lingli Liu $^{1} \cdot$ Zehong Cui ${ }^{1} \cdot$ Hongjun Wang ${ }^{1} \cdot$ Teng $\mathrm{Li}^{2} \cdot$ Lijiang Duan $^{1} \cdot$ Youyou Cheng ${ }^{2} \cdot$ Penghui Su$^{1}$. \\ Ming $\mathrm{Li}^{1} \cdot$ Xiaoyi Wei ${ }^{1}$
}

Received: 12 March 2021 / Accepted: 25 June 2021 / Published online: 2 July 2021

(c) The Author(s) 2021

\begin{abstract}
The low-temperature nitrogen adsorption measurement is commonly used to describe the pore structure of porous medium, while the role of degassing temperature in the low-temperature nitrogen adsorption measurement does not attract enough attention, various degassing temperatures may lead to the different pore structure characterization for the same coal. In this study, the low-rank coal collected from Binchang mining area, southwest of Ordos Basin was launched the low-temperature nitrogen adsorption measurement under seven various degassing temperatures $\left(120^{\circ} \mathrm{C}, 150{ }^{\circ} \mathrm{C}, 180{ }^{\circ} \mathrm{C}, 210{ }^{\circ} \mathrm{C}, 240^{\circ} \mathrm{C}\right.$, $270{ }^{\circ} \mathrm{C}$ and $300^{\circ} \mathrm{C}$ ), respectively, the dynamic change of the pore structure under refined upgrading degassing temperatures are studied, and it was also quantitative evaluated with the multi-fractal theory. The results show that the pore specific surface area and pore volume decrease linearly with the increased degassing temperatures, ranges from 12.53 to $2.16 \mathrm{~m}^{2} / \mathrm{g}$ and 0.01539 to $0.00535 \mathrm{~cm}^{3} / \mathrm{g}$, respectively. While the average pore aperture features the contrary characteristics (various from 4.9151 to $9.9159 \mathrm{~nm}$ ), indicating the pore structure has been changed during the refined upgrading degassing temperatures. With the upgrading degassing temperatures, the sizes of hysteresis loop decrease, and the connectivity of pore structure enhanced. The multi-fractal dimension and multi-fractal spectrum could better present the partial abnormal of pore structure during the refined upgrading degassing temperatures, and the quality index, $D_{\mathrm{q}}$ spectrum, $D_{-10}-D_{10}$ and multi-fractal spectrum could describe the homogeneity and connectivity of the pores finely. The degassing temperatures of $150{ }^{\circ} \mathrm{C}, 180{ }^{\circ} \mathrm{C}$ and $270{ }^{\circ} \mathrm{C}$ are selected as three knee points, which can reflect the partial abnormal of the pore structure during the refined upgrading degassing temperatures. Under the lower degassing temperature $\left(<150{ }^{\circ} \mathrm{C}\right)$, the homogeneity and connectivity of the pore feature a certain increase, following that it presents stable when the degassing temperatures various from 150 to $180^{\circ} \mathrm{C}$. The homogeneity and connectivity of the pore would further enhanced until the degassing temperature reaches to $270{ }^{\circ} \mathrm{C}$. Because of the melting of the pore when the degassing temperature exceeds $270{ }^{\circ} \mathrm{C}$, the complexity of pore structure increased. In this study, we advise the degassing temperature for low-temperature nitrogen adsorption measurement of low-rank coal should not exceed $120^{\circ} \mathrm{C}$.
\end{abstract}

Keywords Degassing temperature $\cdot$ Pore structure $\cdot$ Homogeneity and connectivity of pore $\cdot$ Multi-fractal

\section{Introduction}

Coal is a natural porous medium with complexity pore structure, and the development and distribution of pores with various apertures contribute significantly to the

Teng Li

liteng2052@163.com

1 PetroChina Research Institute of Petroleum Exploration and Development, Beijing 10083, China

2 College of Petroleum Engineering, Xi' an Shiyou University, Xi'an 710065 , China seepage and migrate of methane. There are various methods to acquire the pore structure parameters of coal, and the low-temperature nitrogen adsorption $\left(\mathrm{LP}-\mathrm{N}_{2} \mathrm{~A}\right)$ is one of the most useful and effective tool, especially that for the low- and middle-rank coal. When the $\mathrm{LP}-\mathrm{N}_{2} \mathrm{~A}$ is used to study the pore structure of the coal, the coal is commonly pretreated under vacuum with a certain temperature, which is named as degassing temperature. Commonly, the degassing temperatures used by the previous researchers for the porous mediums are different, such as $110^{\circ} \mathrm{C}$ for Devonian shale (Luffel and Guidry 1992), $110{ }^{\circ} \mathrm{C}$ for coal beds in the Eastern Interior Basin (Mardon et al. 2014), $90{ }^{\circ} \mathrm{C}$ for 
Run of Mine (Okolo et al. 2015), $80{ }^{\circ} \mathrm{C}$ for coal samples in Hancheng Block (Zhao et al. 2016), $105^{\circ} \mathrm{C}$ for coal samples in western Guizhou (Chen et al. 2018), and so on. Li et al. (2020, 2021a, b) have studied the dynamic change of pore structure under various degassing temperature, the thermal effect on the pore structure and the thermal evolution of meso-pore structure under various degassing temperatures have been discussed, while these studies do not pay much attention on the quantitative characterization of the dynamic change of the pore structure.

The porous medium features complexity pore structure, the conventional Euclid language could not present the pore structure characteristics in coal and shale ideally. Mandelbrot (1967) built and developed the fractal theory when studied the length of the coast of Britain, which provide a useful tool to quantitative describe the change rule of the object with irregular shape (Grassberger and Procaccia 1983; Halsey et al. 1987). In the field of unconventional oil and gas, the geology characteristics commonly feature strong heterogeneity and nonlinear characteristics, such as the micro-fractures, cleats (Hirata et al. 1987; Panahi and Cheng 2004; Li et al. 2007), pore structure (Yao et al. 2008), and so on. These characteristics present a certain fractal behavior. The fractal theory has been widely used in analyzing the pore structure of porous mediums as a nonlinear science (Naveen et al. 2018). For the pores in the porous mediums, even the pores under nano-scale also features complexity and refined structure, which is similar to the pores with mm-scale, this is named as similarity. The Sierpinski model, thermodynamic model, FHH model, Langmuir model and fully penetrable sphere model are quite commonly used in the fractal theory (Liu et al. 2015; Kumar et al. 2019; Li et al. 2019; Ma et al. 2019; Mahamud et al. 2019; Mangi et al. 2020; Gonzalez 2021), and the single fractal and multi-fractal methods are frequently used to analyse the pore structure in coal and shale. The single fractal could only reflect the whole characteristics of the pore structure, while the multi-fractal could describe both the whole and partial characteristics of pore structure. Caniego et al. (2000) studied the singularity features of pore size soli distribution and found that the reveal dimensional analysis was quite useful to characterize the soil structures, and the multi-fractural parameters to evaluate the soil structure stability (Ferreiro and Vazquez 2010), and the multi-fractal model could refine the vertical spatial heterogeneity of porous medium significantly (Martinez et al. 2010; Ghanbarian et al. 2015). With the detailed analysis of the singularity exponent parameter, generalized dimension parameter, information dimension and correlation dimension, the tight sandstone reservoir types are classified, which could guide the development of the tight sandstone gas (Jiang et al. 2018). With the multi-fractal parameters of $f(\alpha)$ and $H$, the heterogeneity and connectivity of the pores in the Upper-Lower Bakken shale were also distinguished (Liu et al. 2018).

The multi-fractal has been widely used to describe the complexity structure characteristics from the nano-scale pores to km-scale faults (Hirabayashi et al. 1992; Kiyashchenko et al. 2004; Panahi and Cheng 2004; Xie et al. 2007; Zhao et al. 2011), especially for the former one (Shivakumar et al. 1996; Li et al. 2015; Liu et al. 2018; Song et al. 2018; Zhang et al. 2021). Zheng et al. (2019) provided a new method to calculate the NMR $T_{2}$ cutoff value in the coal with the multi-fractal theory, and the NMR $T_{2}$ cutoff values feature significantly linear relationships with the fractal dimensions (Zhao et al. 2021), which could be used to analyse the distribution of fluids in the coal (Zhang et al. 2021). With the gas adsorption method and the multi-fractal theory, the multilayer adsorption and porosimetry effect of the gas on the pore structure are studied by Wang et al. (2019). According to the distribution of fractures and the density of the fractures, the multi-fractal theory could present the connectivity of the fractures based on the images, which could predict the effective seepage area of coalbed methane (Chen et al. 2017; Cheng et al. 2020). Li et al. (2015) and Song et al. (2018) studied the pore structure of the tectonically deformed coal with the multi-fractal theory found that the pore aperture decreased, and the pore connectivity of the pores in the deformed coal is poor, because the tectonic deformation contributes to the concentrate of the pores. Zhang et al. (2021) studied the pore structure characteristics in the shale with multi-fractal and found that the TOC features linear negative correlation with the $H$ and $\Delta \alpha$. The porosity of the porous mediums presents significantly relationships with the fractal dimensions (Gonzalez 2021). The measurements method for the pore structure, such as the mercury intrusion porosimetry (MIP), low-field NMR spectral analysis (LFNMR) and gas adsorption, could be used to analyse the pore structure of tight sandstone, coal and shale (Lai et al. 2015; Liu et al. 2018; Guo et al. 2019; Yuan and Rezaee 2019; Wang et al. 2020). Hou et al. (2020) reported that the high probability measure areas are much more sensitive when the LFNMR was used to study the pore structure of the coal beds, and the other multi-fractal parameters, such as $A, D_{0}-D_{1}$ and $D_{0}-D_{2}$ are also quite useful.

Although substantial works have been done on the pore structures of porous medium with multi-fractal theory, the quantitative evaluation of the homogeneity and connectivity of the pores in the coal with multi-fractal method under refined upgrading degassing temperatures is still lack. In this study, the low-rank coal collected from Binchang mining area, southwest of Ordos Basin was ground with a size of 60-80 mesh, and the LP- $\mathrm{N}_{2} \mathrm{~A}$ measurements with various degassing temperatures were launched to investigate the dynamic change of the pore structure. Finally, the quantitative evaluation of the homogeneity and connectivity of the 
pores during the refined upgrading degassing temperatures were carried out.

\section{Samples and method}

\section{Measurements}

The coal sample was collected from Binchang mining area, southwest of Ordos Basin, China. The reflectance of vitrinite in coal $\left(R_{\mathrm{o}, \max }\right)$, proximate analysis of coal and scanning electron microscope (SEM) are carried out to acknowledge the basic properties of the coal, and the $\mathrm{LP}-\mathrm{N}_{2} \mathrm{~A}$ measurements were launched to acquire the pore structure parameters of the coal.

The coal sample was polished, and the Carl Zeiss Primotech optical microscope was used to measure the $R_{\mathrm{o} \text {,max }}$ of coal, and the method of determining microscopically the reflectance of vitrinite in coal (GB/T 6948-2008, Chinese standard) was taken as reference. The coal sample was polished with a size of 200 mesh, with the proximate analysis of coal (GB/T 212-2008, Chinese standard) and KY-2000 instrument, the proximate analysis of coal was measured. For the SEM measurement, the coal sample was first polished with a size of $10 \mathrm{~mm} \times 10 \mathrm{~mm} \times 1 \mathrm{~mm}$; following that, the coal sample was sprayed with gold, the pore shape and pore types were viewed with the MAIA3 model 2016 (LM) scanning electron microscope for ultra-high resolution field emission scanning electron microscope, and the gold-plated thickness measurement by SEM (GB/T 17722-1999, Chinese standard) was consulted. When it comes to the LP$\mathrm{N}_{2} \mathrm{~A}$ measurements, seven degassing temperatures were set, $120^{\circ} \mathrm{C}, 150{ }^{\circ} \mathrm{C}, 180^{\circ} \mathrm{C}, 210{ }^{\circ} \mathrm{C}, 240{ }^{\circ} \mathrm{C}, 270{ }^{\circ} \mathrm{C}$ and $300{ }^{\circ} \mathrm{C}$, respectively, and the $\mathrm{LP}-\mathrm{N}_{2} \mathrm{~A}$ measurements were launched on the TriStar II Plus Series adsorption instrument according to the determination of the specific surface area of solids by gas adsorption using the BET method (GB/T 19587-2017, Chinese standard). The LP- $\mathrm{N}_{2} \mathrm{~A}$ measurements were measures under $-196^{\circ} \mathrm{C}$ (Fig. 1).

\section{Multi-fractal theory}

The multi-fractal theory includes two equivalent mathematical descriptions, multi-fractal singular spectrum $(\alpha \sim f(\alpha))$ and fractal dimension $\left(q \sim D_{q}\right)$ (Halsey et al. 1987), and various fractal parameters could be used to describe the whole and partial abnormal of pore structure characteristics (Li et al. 2015; Zhang et al. 2021). For the gas adsorption measurement, the distribution of the relative pressure would be divided into several boxes with equal
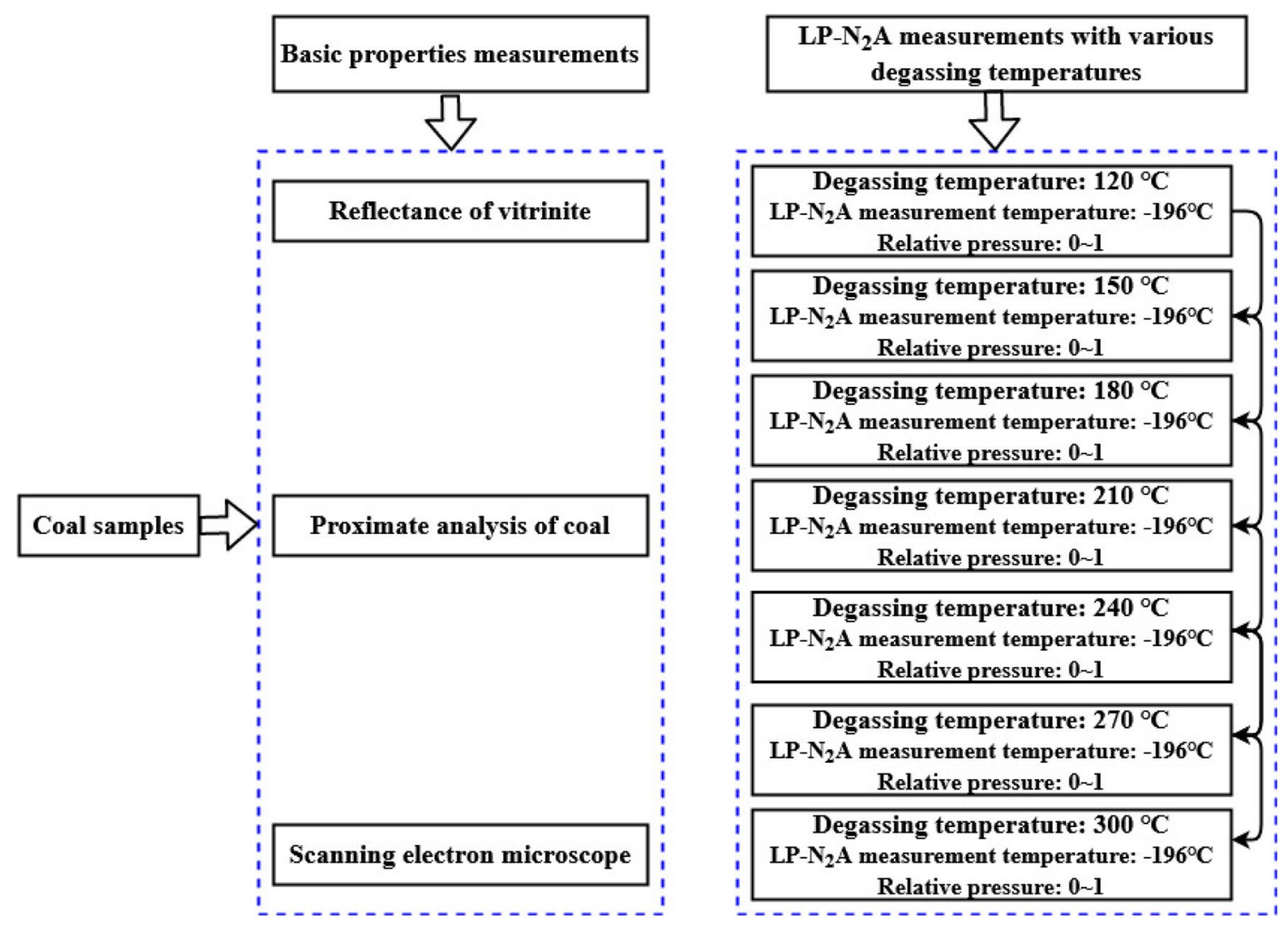

Fig. 1 The flow chart of measurements in this study 
length, and the size of the box is presented as $\varepsilon$ (Liu et al. 2018). Aims to the relative pressure, the probability distribution function $\left(P_{i}(\varepsilon)\right)$ of No. $i$ box could be defined as:

$P_{i}(\varepsilon)=\frac{N_{i}(\varepsilon)}{N_{t}}$

where $N_{i}(\varepsilon)$ is the adsorbed quantity in the No. $i$ box, $i=1$, $2,3, \ldots ; N_{t}$ is the total adsorbed quantity. $P_{i}(\varepsilon)$ could also be featured with the exponential function as:

$P_{i}(\varepsilon) \sim \varepsilon^{a_{i}}$

where $\alpha_{i}$ is the singular index, which can reflect the partial singular strengthen of $P_{i}(\varepsilon)$ (Vazquez et al. 2008). The quantity of subintervals with the same probability of $\alpha$ could be recorded as $N_{\alpha}(\varepsilon)$. The smaller the size of $\varepsilon$, the greater $N_{\alpha}(\varepsilon)$ would be, and the $N_{\alpha}(\varepsilon)$ could also be transformed as:

$N_{\alpha}(\varepsilon) \sim \varepsilon^{-f(\alpha)}$

where $f(\alpha)$ is the fractal dimensions labeled by singular index $\alpha$, the multi-fractal singular spectrum with the relationships between $f(\alpha)$ and $\alpha$, which can reflect the partial abnormal of the adsorbed quantity in the various pores with different pore apertures. $\alpha(q)$ and $f(\alpha)$ could be acquired with Eqs. (4) and (5) (Chhabra and Jensen 1989),

$a(q) \propto \frac{1}{\lg \varepsilon}\left[\sum_{i=1}^{N(\varepsilon)} \chi_{i}(q, \varepsilon) \lg \left(P_{i} \varepsilon\right)\right]$

$f(\alpha) \propto \frac{1}{\lg \varepsilon}\left[\sum_{i=1}^{N(\varepsilon)} \chi_{i}(q, \varepsilon) \lg \chi_{i}(q, \varepsilon)\right]$

$\chi_{i}(q, \varepsilon)=P_{i}^{q}(\varepsilon) / \sum_{i=1}^{N(\varepsilon)} P_{i}^{q}(\varepsilon)$

where $q$ is the order of the statistical operator $(-\infty<q<+\infty)$. In this study, $q$ is the integer ranges from -10 to 10 with a step length of 1 . For the multi-fractal theory, $\chi_{i}(q, \varepsilon)$ is the partition function, and it could also be rewritten as:

$\chi(q, \varepsilon)=\sum_{i=1}^{N(\varepsilon)} P_{i}^{q}(\varepsilon) \sim e^{\tau(q)}$

or

$\tau(q)=\lim _{\varepsilon \rightarrow 0} \frac{\lg \chi(q, \varepsilon)}{\lg \varepsilon}$

where $\tau(q)$ is the quality index. The relationship between fractal dimension $\left(D_{q}\right)$ and $q$ could be obtained as:
$D_{q}=\frac{\tau(q)}{q-1}(q \neq 1)$

When $q>0$, it commonly reflect high probability zone of the distribution of pores. While, $q<0$ means the low probability zone of the distribution of pores (Caniego et al. 2003; Vazquez et al. 2008; Li et al. 2015). In order to ensure the continuity of $D_{q}, D_{1}$ can be acquired from the L'hospital rule (Li et al. 2015),

$D_{1}=\lim _{\varepsilon \rightarrow 0} \frac{1}{\lg \varepsilon}\left\{\sum_{i=1}^{N(\varepsilon)} P_{i}(1, \varepsilon) \lg \left[P_{i}(1, \varepsilon)\right]\right\}$

Then, series of $\left(q, D_{q}\right)$ could be obtained, and the $q \sim D_{q}$ fractal dimension spectrum could be acquired. $D_{1}$ is the information dimension, and $D_{2}$ is the related dimension (Song et al. 2018). $D_{1}$ can feature the concentration degree of pores with various apertures, the smaller $D_{1}$ means the pores would be mainly concentrated in partial apertures. For $D_{2}$, it mainly presents the connectivity of the pores with various apertures, the greater $D_{2}$ is, the better pore connectivity would be.

\section{Results and discussion}

\section{The basic properties of coal}

The average $R_{\mathrm{o}, \max }$ of the coal sample is $0.62 \%$, the average content of moisture and ash yield are $5.07 \%$ and $17.56 \%$, respectively, while the average content of volatile matters is quite high, which reaches to $38.18 \%$ (Table 1), meaning the coal sample from Binchang mining area is the low-rank coal.

The pores in the coal sample are mainly plant tissue pores and gas pores (Fig. 2). The plant tissue pores are squeezed and deformed (Fig. 2a), indicating the sediment compaction has significantly influence the shape of the pores. The gas pores mainly developed on the surface of the coal matrix (Fig. 2b), meaning a brief hydrocarbon generation. Besides the gas pores, there are also a certain amount of in-organic minerals distributed on the surface of coal matrix (Fig. 2). It can be found that the pores mainly developed in isolation, indicating the poor connectivity of pores in the coal.

Table 1 The basic properties parameters of the coal in Binchang mining area

\begin{tabular}{lllll}
\hline Samples & $R_{\text {o, } \max } \%$ & $M_{\text {ad }} \%$ & $A_{\mathrm{d}} \%$ & $V_{\text {daf }} \%$ \\
\hline S1 & 0.63 & 5.16 & 17.53 & 38.22 \\
S2 & 0.61 & 4.98 & 17.58 & 38.14 \\
Average & 0.62 & 5.07 & 17.56 & 38.18 \\
\hline
\end{tabular}



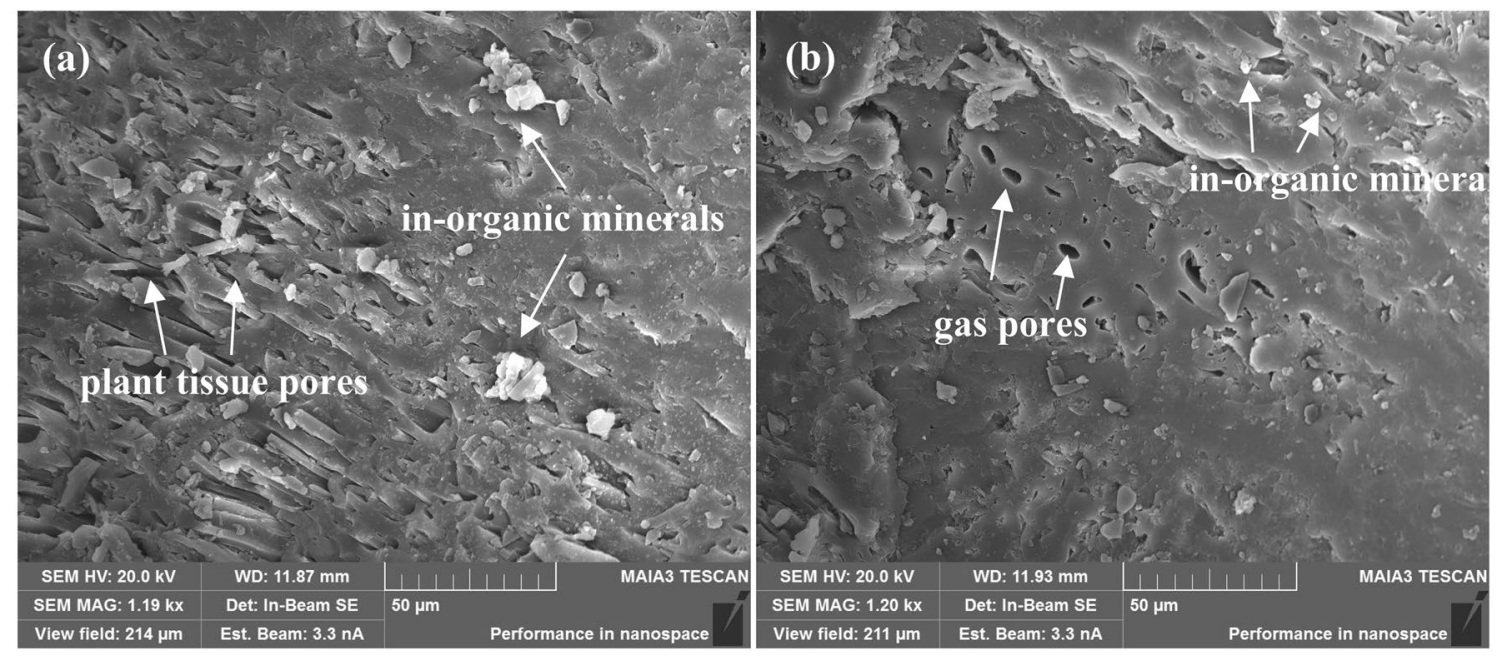

Fig. 2 The SEM of coal samples in Binchang coal mining

\section{Pore structure characteristics from the $L P-N_{2} A$ measurements}

It can be found that the adsorption/desorption curves for the same coal sample are different under different degassing temperatures (Fig. 3). When the degassing temperature is lower than $240{ }^{\circ} \mathrm{C}$, the adsorption curve features as obvious up-bulge as the relative pressure is less than 0.1 . With the continuously increase of the relative pressure, the adsorbed quantity of the coal sample increases linearly. At relative pressure of 0.9 , the adsorbed quantity increase sharply. The desorption curve also features sharply decrease at the relative pressure ranges from 0.9 to 1 , and the desorption curve approximately parallels to the $X$-axis when the relative pressure decreased to 0.5 , and there is an obviously knee point of the adsorbed quantity at the relative pressure of 0.5 . With the continuously decrease of the relative pressure, the desorption curve almost parallels to the adsorption curve. Under
Fig. 3 The adsorption/desorption curves of coal sample under various degassing temperatures

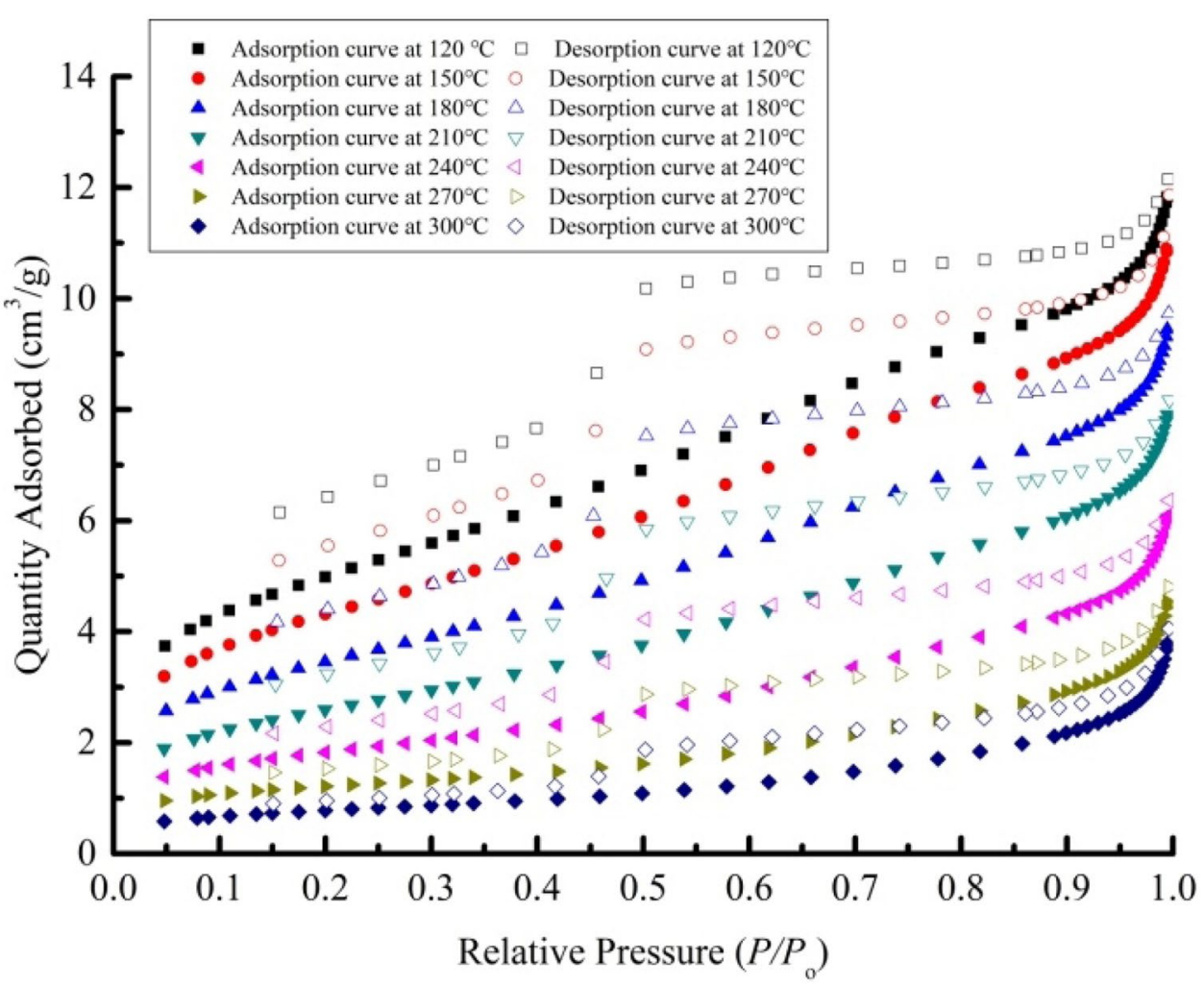

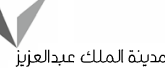
KACST ميدية 
the degassing temperatures range from 120 to $240{ }^{\circ} \mathrm{C}$, the hysteresis loop mainly features the $\mathrm{H}_{3}$ type. When the degassing temperature exceeds $240{ }^{\circ} \mathrm{C}$, the adsorption curve is almost parallels to the $X$-axis, the increase of the adsorbed quantity is slow, and when the relative pressure reaches to 0.9 , the adsorbed quantity increases sharply. The desorption curve is almost parallels to the adsorption curve, and the knee point at relative pressure 0.5 is also not obvious. The hysteresis loop for the coal sample under high degassing temperature features as $\mathrm{H}_{4}$ type (Fig. 3).

With the increased degassing temperatures, not only the adsorption/desorption curves, but also the pore structure is dynamic change. The cumulative pore specific surface area and cumulative pore volume feature as continuously decrease, the incremental pore specific surface area and incremental pore volume present contrary, the pores with aperture below $20 \mathrm{~nm}$ contribute dominantly to the decrease of pore volume and pore specific surface area (Fig. 4). With the increased degassing temperatures, the BET specific surface area, BJH pore volume and maximum adsorbed quantity feature linearly decrease, while the average pore aperture features contrary, especially when the degassing
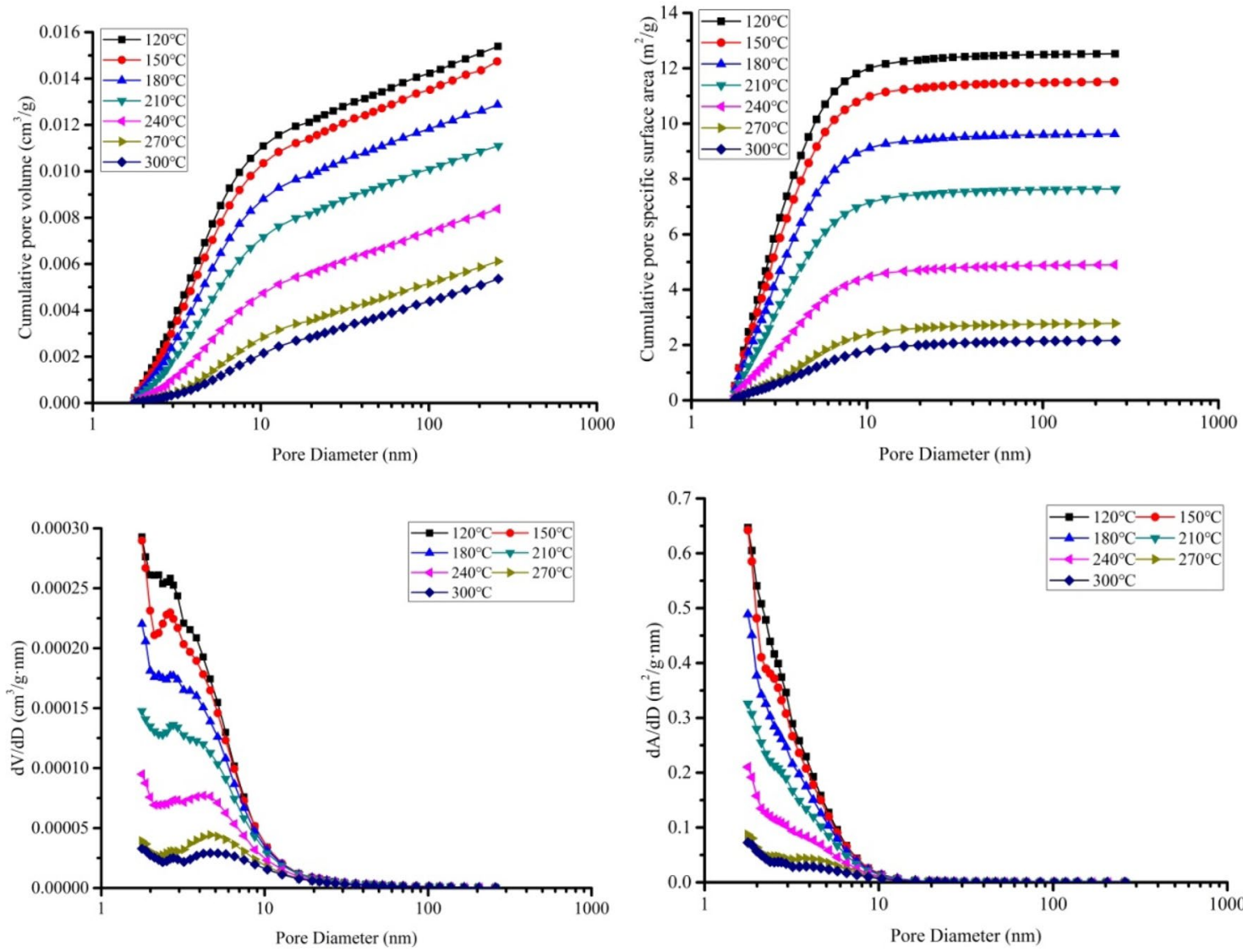

temperature reaches to $270{ }^{\circ} \mathrm{C}$, the average pore aperture increases sharply (Fig. 5).

For the $\mathrm{LP}-\mathrm{N}_{2} \mathrm{~A}$ measurements of the coal sample, the only variable is the degassing temperatures. Due to the

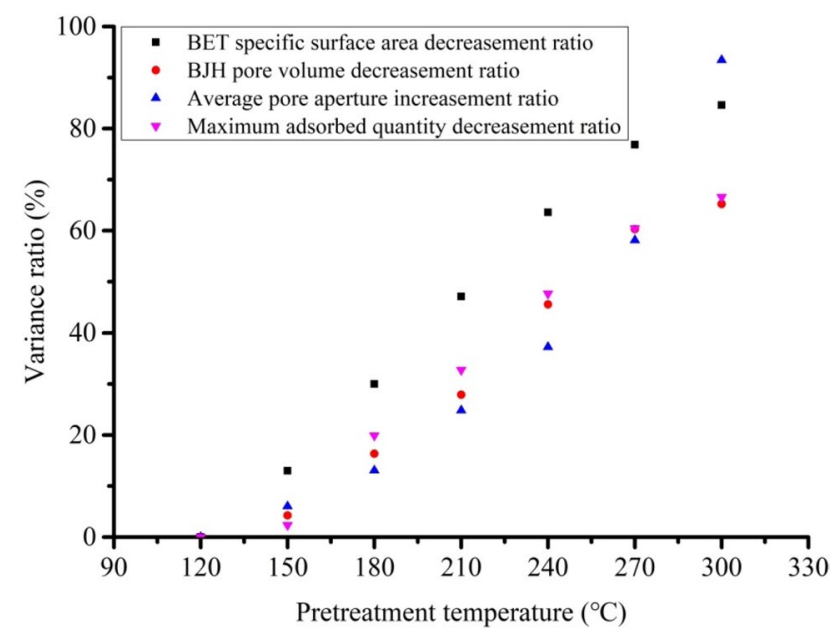

Fig. 5 Dynamic change of pore structure parameters under various degassing temperatures

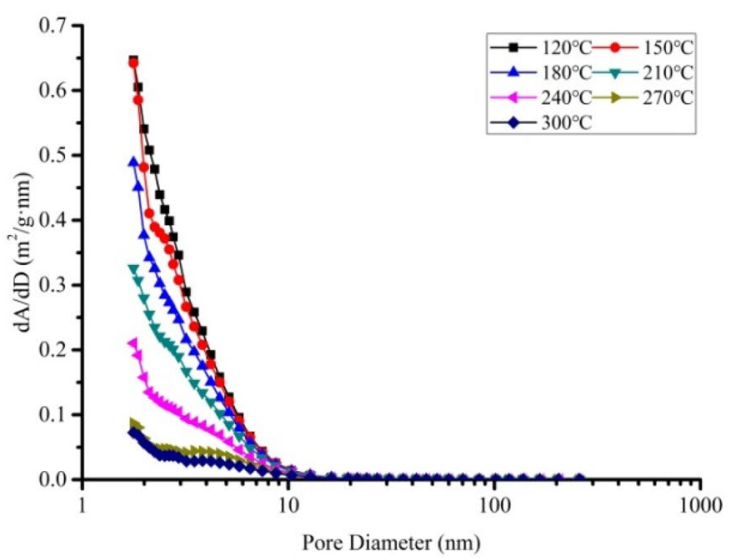

Fig. 4 Dynamic change of pore specific surface area and pore volume under various degassing temperatures 
low maturity of the Binchang coal sample, it presents high content of volatile matters, and the volatile matters may be decomposed under high degassing temperatures. With the continuously decrease of the volatile matters in the lowrank coal, the pore structure would be changed. The degassing temperatures and content of volatile matters may be the essential factors that alter the pore structure of low-rank coal.

\section{Quantitative characterization of pore structure}

\section{The hysteresis loop}

The various adsorption/desorption curves under various degassing temperatures indicates that the degassing temperature features significantly influence on the pore structure of coal. With the increased degassing temperatures, the hysteresis loop obviously decreases, indicating the amount of the ink-bottle pore decreases, and the pore connectivity has been enhanced. In order to describe the size of the hysteresis loop quantitative, the hysteresis loop aperture was utilized in this study. The greater hysteresis loop aperture of the coal, the more complexity pore structure would be. The hysteresis loop could be defined as:

$\dot{d}_{\left(q_{d e}-q_{a d}\right)}=q_{d e(i)}-q_{a d(i)}$

where $d_{\left(q_{d e}-q_{d d}\right)}$ is the hysteresis loop aperture at relative pressure of $i, \mathrm{~cm}^{3} / \mathrm{g} ; q_{d e(i)}$ is the adsorbed quantity from the desorption curve relative pressure of $i, \mathrm{~cm}^{3} / \mathrm{g} ; q_{a d(i)}$ is the adsorbed quantity from the adsorption curve at relative pressure of $i, \mathrm{~cm}^{3} / \mathrm{g}$.

The hysteresis loop aperture is almost stable when the relative pressure is lower than 0.5 . When the relative pressure exceeds 0.5 , there is the obvious increase of the hysteresis loop aperture, and the increase of the hysteresis loop aperture is significantly. With the increase of the degassing temperatures, the hysteresis loop aperture features continuously decrease, especially when the degassing temperature exceeds $150{ }^{\circ} \mathrm{C}$, the hysteresis loop aperture decreases sharply at high relative pressure zone. Under the low relative pressure, although there is a decrease of the hysteresis loop aperture, it is not obvious. According to the Kelvin equation, when the relative pressure exceeds 0.5 , the pore aperture would exceed $5 \mathrm{~nm}$, it indicates that the increased degassing temperature mainly influenced the pores with aperture greater than $5 \mathrm{~nm}$ (Fig. 6).

\section{Multi-fractal characteristics of pore structure}

There is a significantly linearly relationship between $\ln \varepsilon$ and $\ln \chi(q, \varepsilon)$, indicating $\varepsilon$ and $\chi(q, \varepsilon)$ feature the scaling invariance, then the pore structure of the coal under various

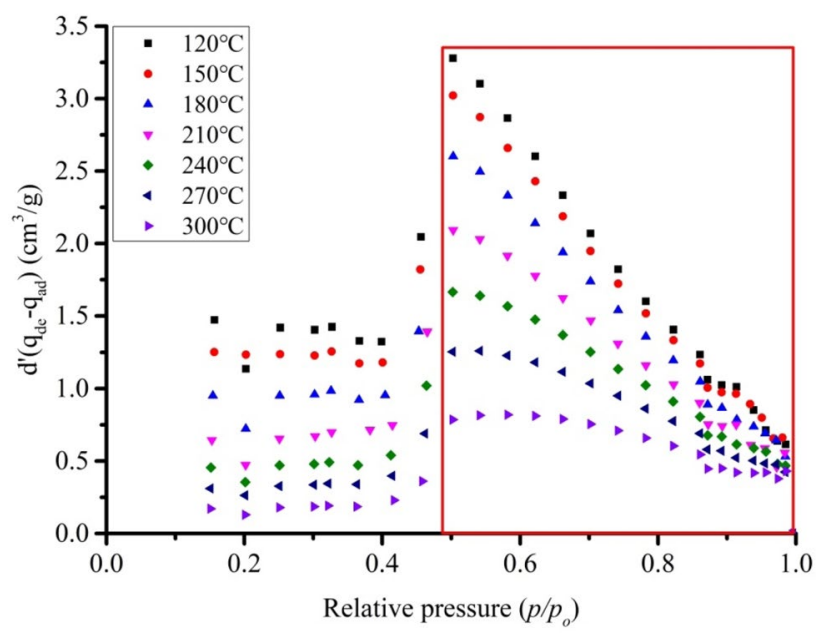

Fig. 6 The hysteresis loop aperture of coal sample under various degassing temperatures

degassing temperatures features the multi-fractal characteristics (Song et al. 2018) (Fig. 7).

\section{The quality index}

$\tau(q)$ features the distribution of pore. For the single fractal, the relationship between $\tau(q)$ and $q$ is linear, indicating the homogeneity of the pore structure. For the multi-fractal, the relationship between $\tau(q)$ and $q$ is nonlinear. It can be found that $\tau(q-)>\tau(q+)$, meaning the multi-fractal characteristics of the pore structure under various degassing temperatures (Fig. 8). The slope of $\tau(q) \sim q$ at $q>0$ is different with that of $\tau(q) \sim q$ at $q<0$, meaning the heterogeneity of the pore structure. When $q<0, \tau(q)$ is almost coincided, $\tau(q) \sim q$ features almost-linear. With the increased degassing temperatures, the value of $\tau(q)$ is increased, but it is not obvious. When $q>0$, the differences among the coal sample under various degassing temperatures are obvious, and the $\tau(q) \sim q$ tends to linear with the increased degassing temperatures, indicating the pore structure tends to be homogeneity. $\tau(q)$ is lower than that at higher degassing temperatures, it indicates that the homogeneity of the pore structure is enhanced with the increased degassing temperatures.

\section{The fractal dimensions}

The shape of $D_{q}$ spectrum and the sizes of $D_{-10}-D_{10}$ could describe the partial difference of porosity at various pore apertures (Halsey et al. 1987; Li et al. 2015; Liu et al. 2018). The wider $D_{q}$ spectrum means the greater $D_{-10}-D_{10}$, which indicates the obvious differences of pores in the coal, and the pore structure is complexity. Figure 9 shows that $D_{-10}-D_{10}$ is greatest when the degassing temperature is $120^{\circ} \mathrm{C}$, meaning the maximum pore complexity of pores at the low degassing

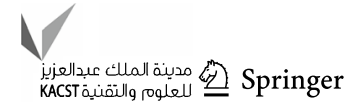


Fig. 7 The double ln curves between $\varepsilon$ and $\chi(q, \varepsilon)$ of coal under various degassing temperatures

temperatures; while the $D_{-10}-D_{10}$ is smallest at the degassing temperature of $300^{\circ} \mathrm{C}$, and the difference of $D_{-10}-D_{10}$ presents continuously decrease with the increased degassing temperatures.

The shape of $D_{q} \sim q$ at various degassing temperatures is different. At the degassing temperature of $120^{\circ} \mathrm{C}$, the shape of $D_{q} \sim q$ features as reverse "S"; while it presents as almostlinear shape at the degassing temperatures of $150{ }^{\circ} \mathrm{C}$ and $180{ }^{\circ} \mathrm{C}$ at $q<0$ zone, and it is still features as reverse " $\mathrm{S}$ " at $q>0$ zone; when the degassing temperature exceeds $210{ }^{\circ} \mathrm{C}$, the $D_{q} \sim q$ presents as almost-linear shape wholly. The left branch and right branch of $D_{q}$ spectrum represent the different information of the pore structure in the coal. Compared with the pore size distribution of the coal sample (Fig. 4), it can be inferred that the right branch $\left(D_{0}-D_{10}\right)$ mainly represent the dynamic change of pore structure with the pores aperture below $20 \mathrm{~nm}$, while the left branch $\left(D_{-10}-D_{0}\right)$ mainly describe the various pore structure of pores aperture greater $20 \mathrm{~nm}$. The almost-linear shape reflect the pore structure is generally homogeneity, and the reverse " $\mathrm{S}$ " shape dominantly represents the complexity pore structure in the coal. It can be found that the pores with apertures greater than $20 \mathrm{~nm}$ is almost stable when the degassing temperature exceeds $150{ }^{\circ} \mathrm{C}$. When it comes to the pores with aperture below $20 \mathrm{~nm}$, there are two obvious knee points at the degassing temperatures of $150{ }^{\circ} \mathrm{C}$ and $270{ }^{\circ} \mathrm{C}$. There is a certain enhancement of the homogeneity of pore structure at the degassing temperature of $150{ }^{\circ} \mathrm{C}$, and then the homogeneity of pore structure is stable when the degassing temperature increased to $180^{\circ} \mathrm{C}$. The homogeneity of pore structure presents a sharply increase when the degassing temperature reaches to $270^{\circ} \mathrm{C}$, and it reaches to the maximum (Fig. 9).

The information dimension $D_{1}$ mainly represents the average distribution of pores with various apertures, the smaller $D_{1}$ means the poor pore size distribution, the pores mainly concentrated with a certain pore apertures. $D_{1}$ mainly ranges from 0.9530 to 0.9932 (Table 2), $D_{1}$ is quite close to 1 , indicating that the homogeneity of the pores is increased. With the increased degassing temperatures, the pore size distribution of the pores is enhanced, and the average pore aperture is also increased (Fig. 5). However, it should notice that $D_{1}$ features a certain decrease when the degassing temperature reaches to $300{ }^{\circ} \mathrm{C}$ (Table 2), indicating the homogeneity of pore structure decreases at the higher degassing temperature. The related dimension $D_{2}$ could represent the connectivity of pores in the coal admirably. The higher $D_{2}$ value commonly features the better pore connectivity. With the continuously increase of the degassing temperatures, the $D_{2}$ value increases, it can be inferred that the increased degassing temperatures could also increase the pore connectivity

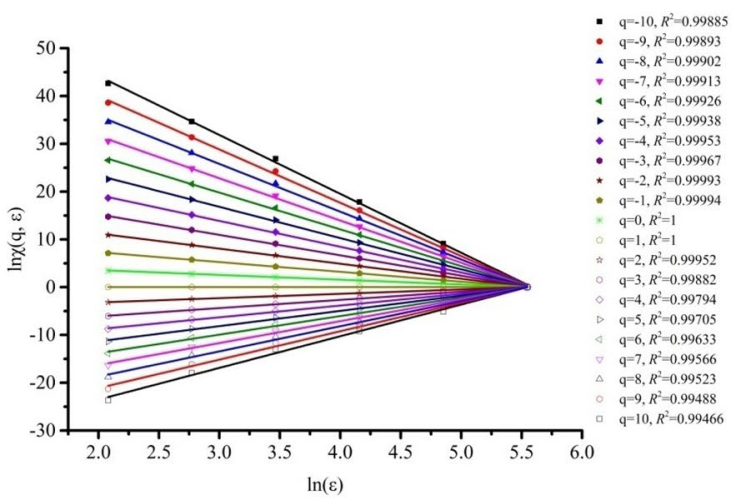

$120^{\circ} \mathrm{C}$

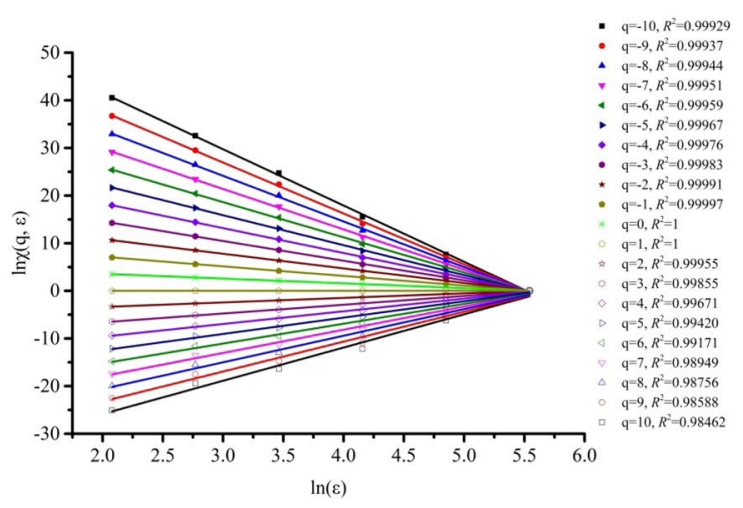

$150^{\circ} \mathrm{C}$

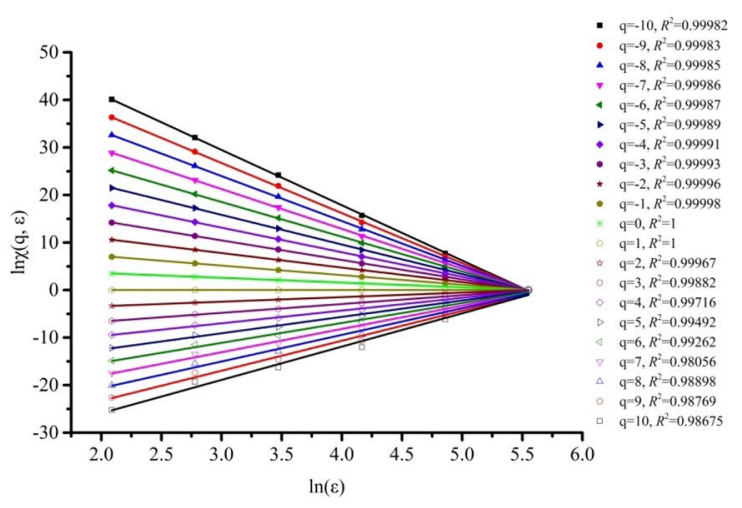

$180^{\circ} \mathrm{C}$

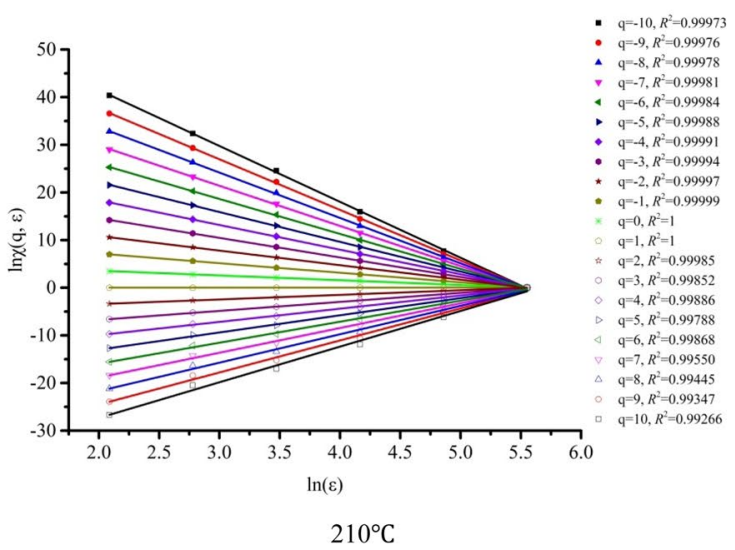



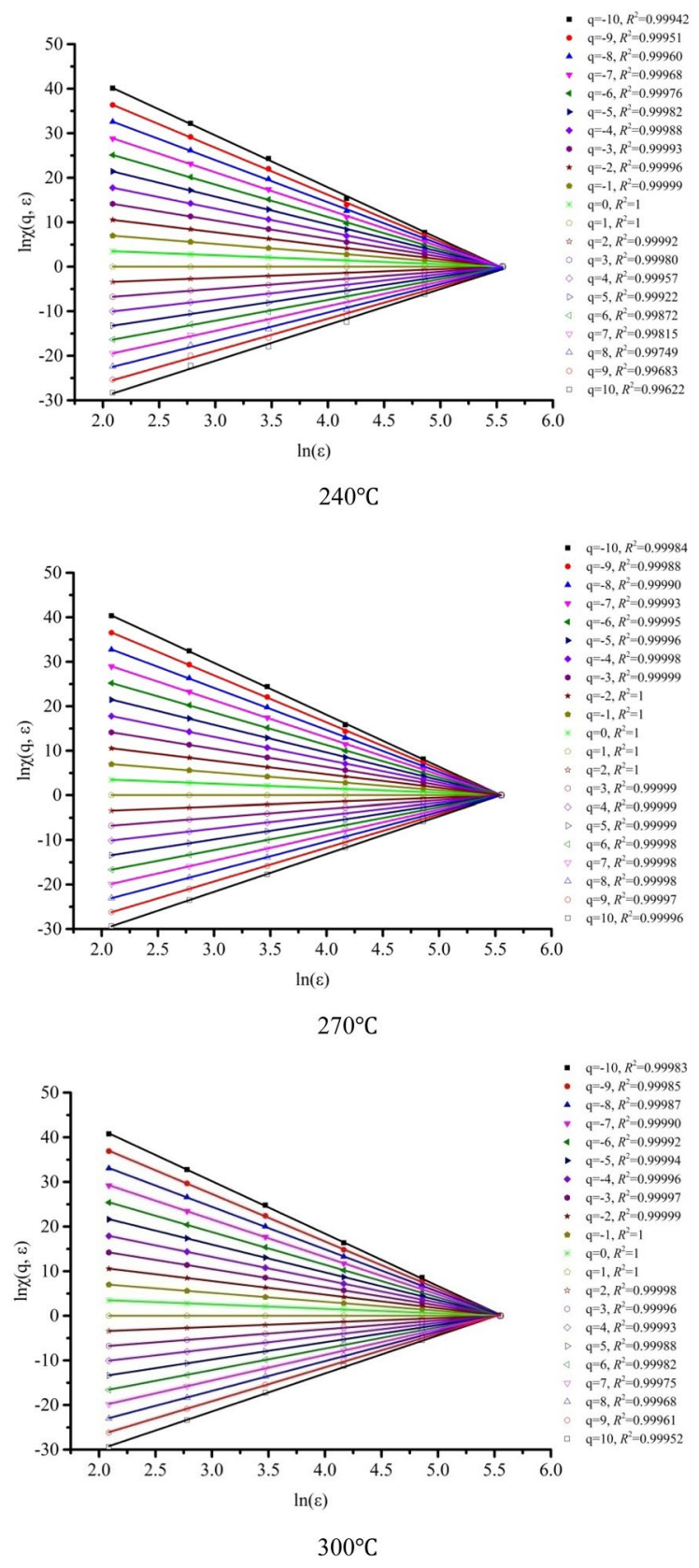

Fig. 7 (continued)

in coal. Similar, the $D_{2}$ value also decreases at the degassing temperature of $300{ }^{\circ} \mathrm{C}$, the pore connectivity features a certain reduce at high degassing temperature. It can be found that the $D_{0}-D_{10}$ is higher than that of $D_{-10}-D_{0}$ at the same degassing temperature. Therefore, the complexity of the pore is mainly reflected by the pores with aperture below $20 \mathrm{~nm}$, and the distribution of the pores with aperture greater than $20 \mathrm{~nm}$ just accelerate the complexity of pores in the coal.

With the increased degassing temperatures, the pores in the coal would be collapsed with the higher temperatures (Li et al. 2020, 2021 a, b), and this may accelerate the

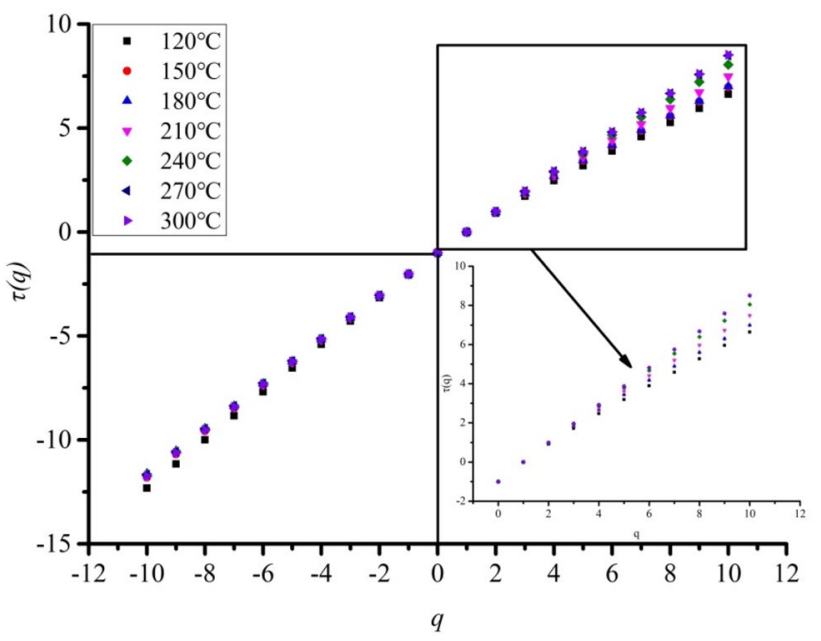

Fig. 8 The $\tau(q)$ of coal under various degassing temperatures

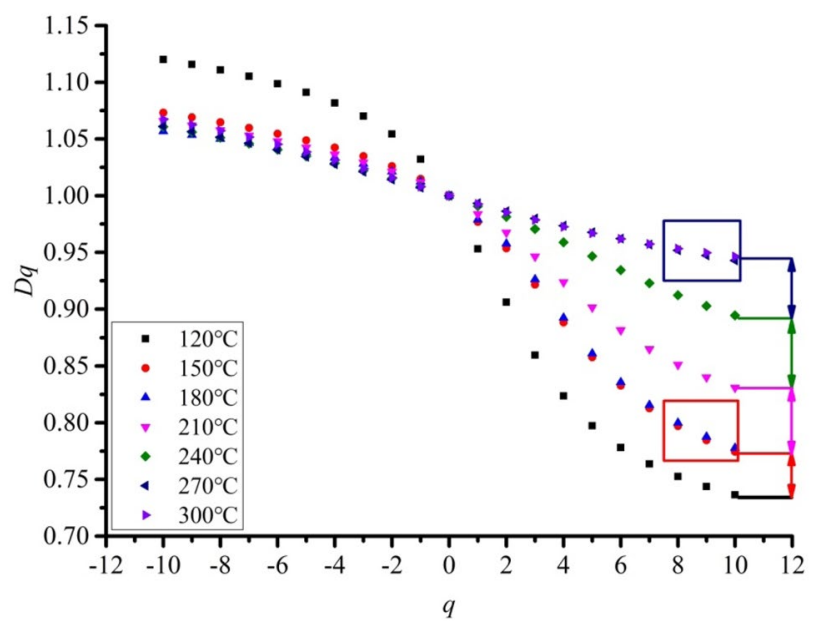

Fig. 9 The fractal dimensions $\left(D_{q}\right)$ spectrum of coal under various degassing temperatures

heterogeneity of the pore structure. However, the collapse of the pores mainly occurs in pores with aperture ranges from 5 to $15 \mathrm{~nm}$ (Li et al. 2020, 2021a, b), the ash in these pores could maintain the shape of the pores, and the connectivity and homogeneity of the pores are enhanced. However, with the increased degassing temperatures, the pores with aperture below $5 \mathrm{~nm}$ begin to collapse, and the supporting of the ash in these pores are weak, which leads to the complexity pore structure (Li et al. (2020).

\section{Multi-fractal spectrum $(a \sim f(a))$}

The $\alpha \sim f(\alpha)$ multi-fractal spectrum features as up-bulge. The singular index $\alpha_{0}$ could provide the pore size distribution characteristics in the coal. The higher $\alpha_{0}$ means the partial fluctuation of pores. It can be found that with the increased 
Table 2 The fractal dimensions parameters of coal

\begin{tabular}{lllllllll}
\hline $\begin{array}{l}\text { Degassing tem- } \\
\text { peratures }\left({ }^{\circ} \mathrm{C}\right)\end{array}$ & $D_{0}$ & $D_{1}$ & $D_{2}$ & $D_{10}$ & $D_{-10}$ & $D_{-10}-D_{10}$ & $D_{0}-D_{10}$ & $D_{-10}-D_{0}$ \\
\hline 120 & 1 & 0.953 & 0.9061 & 0.7364 & 1.1200 & 0.3836 & 0.2636 & 0.1200 \\
150 & 1 & 0.9768 & 0.9536 & 0.7745 & 1.0732 & 0.2987 & 0.2255 & 0.0732 \\
180 & 1 & 0.9788 & 0.9576 & 0.7778 & 1.0567 & 0.2789 & 0.2222 & 0.0567 \\
210 & 1 & 0.9838 & 0.9675 & 0.8309 & 1.0659 & 0.2350 & 0.1691 & 0.0659 \\
240 & 1 & 0.9907 & 0.9814 & 0.8944 & 1.0607 & 0.1663 & 0.1056 & 0.0607 \\
270 & 1 & 0.9932 & 0.9863 & 0.9428 & 1.0612 & 0.1184 & 0.0572 & 0.0612 \\
300 & 1 & 0.9926 & 0.9852 & 0.9463 & 1.0673 & 0.121 & 0.0537 & 0.0673 \\
\hline
\end{tabular}

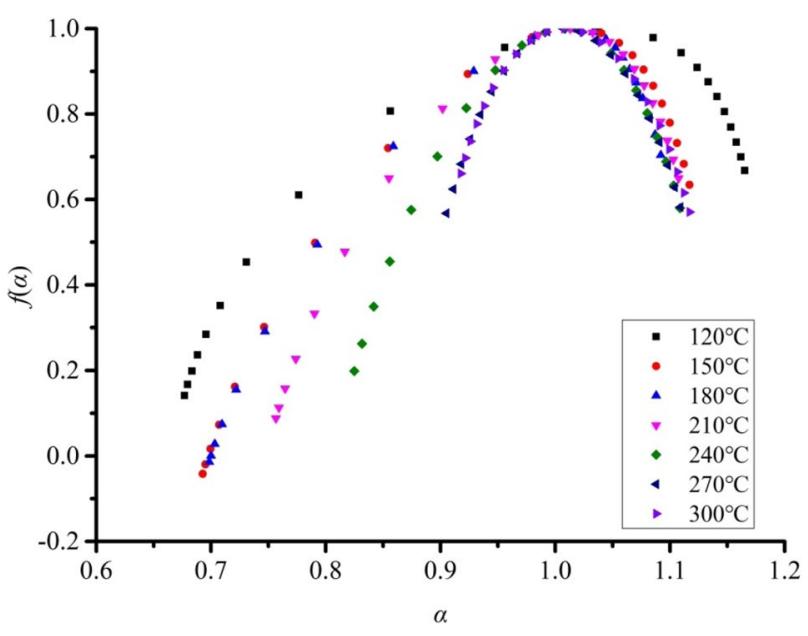

Fig. 10 The curves of $\alpha \sim f(\alpha)$ for coal under various degassing temperatures

degassing temperatures, the value of $\alpha_{0}$ decreases, which reflects the increased homogeneity of the pores in the coal (Fig. 10).

The width of $\alpha \sim f(\alpha)$ multi-fractal spectrum $\left(\alpha_{q_{-}-} \alpha_{q_{+}}\right)$ could present the complexity of the pore size distribution. The wider $\alpha_{q-}-\alpha_{q+}$ is, the stronger heterogeneous of pore structure would be. With the increased degassing temperatures, the $\alpha_{q-}-\alpha_{q+}$ decreases, it means the partial difference of the pore structure is reduced, and the pore structure tends to be simple (Fig. 10). $\alpha_{0}, \alpha_{-10}-\alpha_{0}$ and $\alpha_{0}-\alpha_{10}$ could also represent the various pore structure characteristics in the coal. $\alpha_{0}$ decreases with the increased degassing temperatures, and it reaches to minimum when the degassing temperature is $270{ }^{\circ} \mathrm{C}$; following that, there is a faint increase, indicating a certain increase of the pore structure at high degassing temperature (Table 3 ). The relationship between degassing temperatures and $\alpha_{-10}$ is similar to that of $\alpha_{0}$, while that is contrary for that of $\alpha_{10}$. The deviation of $\alpha \sim f(\alpha)$ also decreases with the increased degassing temperatures. However, it should notice that when the degassing temperature exceeds $240{ }^{\circ} \mathrm{C}$, the deviation of $\alpha \sim f(\alpha)$ changes from right avertence to left avertence (Table 3 ).

\section{Conclusions}

The coal sample was launched the LP- $\mathrm{N}_{2} \mathrm{~A}$ measurements under various degassing temperatures, the dynamic change and quantitative characterization of the pore structure was studied, several conclusions could be acquired.

(1) The degassing temperature could alter the pore structure of the Binchang low-rank coal significantly, this may dominantly relate to the continuously decomposition of volatile matters in the coal. With the increased degassing temperatures, the pore specific surface area and pore volume feature as decrease, while that for the average pore aperture is contrary.
Table 3 The $\alpha \sim f(\alpha)$ multifractal spectrum parameters

\begin{tabular}{lllllll}
\hline $\begin{array}{l}\text { Degassing tem- } \\
\text { peratures }\left({ }^{\circ} \mathrm{C}\right)\end{array}$ & $\alpha_{0}$ & $\alpha_{-10}$ & $\alpha_{10}$ & $\alpha_{-10}-\alpha_{0}$ & $\alpha_{0}-\alpha_{10}$ & $\left(\alpha_{0}-\alpha_{10}\right)-\left(\alpha_{-10}-\alpha_{0}\right)$ \\
\hline 120 & 1.0378 & 1.1653 & 0.6769 & 0.1275 & 0.3609 & 0.2334 \\
150 & 1.0171 & 1.1171 & 0.6929 & 0.1000 & 0.3242 & 0.2242 \\
180 & 1.0146 & 1.0920 & 0.6986 & 0.0774 & 0.3160 & 0.2386 \\
210 & 1.0130 & 1.1075 & 0.7566 & 0.0945 & 0.2564 & 0.1619 \\
240 & 1.0083 & 1.1088 & 0.8249 & 0.1005 & 0.1834 & 0.0829 \\
270 & 1.0070 & 1.1091 & 0.9053 & 0.1021 & 0.1017 & -0.0004 \\
300 & 1.0078 & 1.117 & 0.9177 & 0.1092 & 0.0901 & -0.0191 \\
\hline
\end{tabular}


(2) The higher degassing temperatures does not favor the true pore structure of coal, and the lower degassing temperature $\left(<120^{\circ} \mathrm{C}\right)$ would be suitable degassing temperature.

(3) The multi-fractal model would be an useful tool to describe the dynamic change of pore structure under various degassing temperatures.

The fractal dimension $\left(q \sim D_{q}\right)$ and multi-fractal spectrum $(\alpha \sim f(\alpha))$ are two essential parameters to describe the homogeneity and connectivity of the pores in the coal. The homogeneity and connectivity of the pore features a certain increase when the degassing temperature reaches to $150{ }^{\circ} \mathrm{C}$, and it is almost stable during the degassing temperature raise to $180^{\circ} \mathrm{C}$, and the homogeneity and connectivity of the pore enhance sharply subsequently; because of the collapse of the pores with aperture below $5 \mathrm{~nm}$, the homogeneity and connectivity of the pore decreases when the degassing temperature exceeds $270{ }^{\circ} \mathrm{C}$.

Funding This work was supported by the Natural Science Basic Research Plan in Shaanxi Province of China (Program No. 2019JQ527), and Scientific Research Program Funded by Shaanxi Provincial Education Department (Program No. 20JS116).

\section{Declarations}

Conflict of interest The authors declare that they have no known competing financial interests or personal relationships that could have appeared to influence the work reported in this paper.

Authorship contribution Corresponding author is Teng $\mathrm{Li}$, the all coauthors name order is Jianjun Wang, Lingli Liu, Zehong Cui, Hongjun Wang, Teng Li, Lijiang Duan, Youyou Cheng, Penghui Su, Ming Li, Xiaoyi Wei. TL and YC: Writing - original draft. JW, LL, ZC and HW: Software, Supervision. LD, PS, ML and XW: Investigation.

Open Access This article is licensed under a Creative Commons Attribution 4.0 International License, which permits use, sharing, adaptation, distribution and reproduction in any medium or format, as long as you give appropriate credit to the original author(s) and the source, provide a link to the Creative Commons licence, and indicate if changes were made. The images or other third party material in this article are included in the article's Creative Commons licence, unless indicated otherwise in a credit line to the material. If material is not included in the article's Creative Commons licence and your intended use is not permitted by statutory regulation or exceeds the permitted use, you will need to obtain permission directly from the copyright holder. To view a copy of this licence, visit http://creativecommons.org/licenses/by/4.0/.

\section{References}

Caniego FJ, Martin MA, Jose FS (2003) Rényi dimensions of soil pore size distribution. Geoderma 112:205-216
Caniego J, Martin MA, Martinez FSJ (2000) Singularity features of pore-size soil distribution: singularity strength analysis and entropy spectrum. Fractals 9:305-316

Chen X, Yao G, Cai J, Huang Y, Yuan X (2017) Fractal and multifractal analysis of different hydraulic flow units based on micro-CT images. J Nat Gas Sci Eng 48:145-156

Chen Y, Qin Y, Wei C, Huang L, Shi Q, Wu C, Zhang X (2018) Porosity changes in progressively pulverized anthracite subsamples: implications for the study of closed pore distribution in coals. Fuel 225:612-622

Cheng G, Jiang B, Li M, Li F, Xu S (2020) Quantitative characterization of fracture structure in coal based on image processing and multifractal theory. Int J Coal Geol 228:103566

Chhabra A, Jensen RV (1989) Direct determination of the $f(\alpha)$ singularity spectrum. Phys Rev Lett 62:1327-1330

Ferreiro PJ, Vazquez EV (2010) Multifractal analysis of Hg pore size distributions in soils with contrasting structural stability. Geoderma 160:64-73

Ghanbarian B, Taslimitehrani V, Dong G, Pachepsky YA (2015) Sample dimensions effect on prediction of soil water retention curve and saturated hydraulic conductivity. J Hydrol 528:127-137

Gonzalez JL (2021) Multifractal statistic of porous structures simulated through fully penetrable sphere models. Physica A 567:125695

Grassberger P, Procaccia I (1983) Estimation of the Kolmogorov entropy from a chaotic signal. Phys Rev A 28:2591-2593

Guo X, Huang Z, Zhao L, Han W, Ding C, Sun X, Yan R, Zhang T, Yang X, Wang R (2019) Pore structure and multi-fractal analysis of tight sandstone using MIP, NMR and NMRC methods: a case study from the Kuqa depression, China. J Pet Sci Eng 178:544-558

Halsey TC, Jensen MH, Kadanoff LP, Procaccia I, Shraiman BI (1987) Fractal measures and their singularities: the characterization of strange sets. Nucl Phys B Proc Suppl 2:501-511

Hirabayashi T, Ito K, Yoshii T (1992) Multifractal analysis of earthquakes. Pure Appl Geophys 138:591-610

Hirata T, Satoh T, Ito K (1987) Fractal structure of spatial distribution of micro fracturing in rock. Geophys J R Astron Soc 90:369-374

Hou X, Zhu Y, Chen S, Wang Y, Liu Y (2020) Investigation on pore structure and multifractal of tight sandstone reservoirs in coal bearing strata using LF-NMR measurements. J Pet Sci Eng 187:106757

Jiang Z, Mao Z, Shi Y, Wang D (2018) Multifractal characteristics and classification of tight sandstone reservoirs: a case study from the Triassic Yanchang formation, Ordos Basin, China. Energies 11:2242

Kiyashchenko D, Smimova N, Troyan V, Saengen E, Vallianatos F (2004) Seismic hazard precursory evolution: fractal and multifractal aspects. Phys Chem Earth A/B/C 29:367-378

Kumar S, Mendhe VA, Kamble AD, Varma AK, Mishra DK, Bannerjee M, Buragohain J, Prasad AK (2019) Geochemical attributes, pore structures and fractal characteristics of Barakar shale deposits of Mand-Raigarh Basin, India. Mar Pet Geol 103:377-396

Lai J, Wang G (2015) Fractal analysis of tight gas sandstones using high-pressure mercury intrusion techniques. J Nat Gas Sci Eng 24:185-196

Li T, Cai MF, Cai M (2007) Earthquake-induced unusual gas emission in coalmines-A km-scale in-situ experimental investigation at Laohutai mine. Int J Coal Geol 71:209-224

Li T, Wu CF, Wang ZW (2021) The dynamic change of pore structure for low-rank coal under refined upgrading pretreatment temperatures. Pet Sci 18:430-443

Li T, Wu JJ, Wang XG, Huang H (2021) Particle size effect and temperature effect on the pore structure of low-rank coal. ACS Omega 6:5865-5877

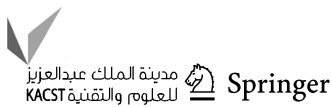


Li T (2020) The dynamic change of pore structure for the low-rank coal with various pretreatment temperatures: a case study from Southwestern Ordos Basin. Geofluids 2020:8879742

Li W, Liu H, Song X (2015) Multifractal analysis of $\mathrm{Hg}$ pore size distributions of tectonically deformed coals. Int J Coal Geol 144-145:138-152

Li Y, Wang Z, Pan Z, Niu X, Yu Y, Meng S (2019) Pore structure and its fractal dimensions of transitional shale: a cross-section from east margin of the Ordos Basin, China. Fuel 241:417-431

Liu K, Ostadhassan M, Zou J, Gentzis T, Rezaee R, Bubach B, Carvajal-Ortiz H (2018) Multifractal analysis of gas adsorption isotherms for pore structure characterization of the Bakken Shale. Fuel 219:296-311

Liu X, Xiong J, Liang L (2015) Investigation of pore structure and fractal characteristics of organic-rich Yanchang formation shale in central China by nitrogen adsorption/desorption analysis. J Nat Gas Sci Eng 22:62-72

Luffel DL, Guidry FK (1992) New core analysis methods for measuring reservoir rock properties of Devonian shale. J Pet Technol 44:1184-1190

Ma X, Guo S, Shi D, Zhou Z, Liu G (2019) Investigation of pore structure and fractal characteristics of marine-continental transitional shales from Longtan Formation using MICP, gas adsorption, and NMR (Guizhou, China). Mar Pet Geol 107:555-571

Mahamud MM, Menendez JM, Alvarez A (2019) Fractal analysis of $\mathrm{CO}_{2}$ and $\mathrm{N}_{2}$ adsorption data to assess textural changes during char gasification. Fuel Process Technol 189:15-27

Mandelbrot B (1967) How long is the coast of Britain? Statistical selfsimilarity and fractional dimension. Science 156:636-638

Mangi HN, Detian Y, Hameed N, Ashraf U, Rajper RH (2020) Pore structure characteristics and fractal dimension analysis of low rank coal in the Lower Indus Basin, SE Pakistan. J Nat Gas Sci Eng 77:103231-1

Mardon SM, Eble CF, Hower JC, Takacs K, Mastalerz M, Bustin RM (2014) Organic pet-rology, geochemistry, gas content and gas composition of Middle Pennsylvanian age coal beds in the Eastern Interior (Illinois) Basin: implications for CBM development and carbon sequestration. Int J Coal Geol 127:56-74

Martínez FSJ, Martín MA, Caniego FJ, Tuller M, Guber A, Pachepsky Y, Garcia-Gutierrez C (2010) Multifractal analysis of discretized $\mathrm{X}$-ray CT images for the characterization of soil macropore structures. Geoderma 156:32-42

Naveen P, Asif M, Ojha K (2018) Integrated fractal description of nanopore structure and its effect on $\mathrm{CH}_{4}$ adsorption on Jharia coals, India. Fuel 232:190-204

Okolo GN, Everson RC, Neomagus HWJP, Roberts MJ, Sakurovs R (2015) Comparing the porosity and surface areas of coal as measured by gas adsorption, mercury intrusion and SAXS techniques. Fuel 141:293-304

Panahi A, Cheng Q (2004) Multifractality as a measure of spatial distribution of geochemical patterns. Math Geol 36:827-846

Shivakumar K, Rao MVMS, Srinivasan CK, Kusunose K (1996) Multifractal analysis of the spatial distribution of area rockbursts at Kolar gold mines. Int J Rock Mech Min Sci Geomech Abstr 33:167-172

Song Y, Jiang B, Shao P, Wu J (2018) Matrix compression and multifractal characterization for tectonically deformed coals by $\mathrm{Hg}$ porosimetry. Fuel 211:661-675

Vazquez VE, Ferreiro JP, Miranda JGV, Gonzalez AP (2008) Multifractal analysis of pore size distributions as affected by simulated rainfall. Vadose Zone J 7:500-511

Wang J, Hu B, Wu D, Dou F, Wang X (2019) A multiscale fractal transport model with multilayer sorption and effective porosity effects. Transp Porous Media 129:25-51

Wang W, Yue D, Eriksson KA, Qu X, Li W, Lv M, Zhang J, Zhang $X$ (2020) Quantification and prediction of pore structures in tight oil reservoirs based on multifractal dimensions from integrated pressure-and rate-controlled porosimetry for the upper Triassic Yanchang Formation, Ordos Basin, China. Energy Fuels 34:4366-4383

Xie S, Cheng Q, Chen G, Chen Z, Bao Z (2007) Application of local singularity in prospecting potential oil/gas targets. Nonlinear Process Geophys 14:285-292

Yao Y, Liu D, Tang D, Tang S, Huang W (2008) Fractal characterization of adsorption-pores of coals from North China: an investigation on $\mathrm{CH}_{4}$ adsorption capacity of coals. Int $\mathrm{J}$ Coal Geol 73:27-42

Yuan Y, Rezaee R (2019) Fractal analysis of the pore structure for clay bound water and potential gas storage in Shales based on NMR and $\mathrm{N}_{2}$ gas adsorption. J Pet Sci Eng 177:756-765

Zhang M, Zhong Q, Li G, Fu X, Duan C, Liu H, Xu H (2021) Fluid distribution and pore structure multifractal characteristics analysis of coal measure mudstone. J Nat Gas Sci Eng 88:103810

Zhao J, Xu H, Tang D, Mathews JP, Li S, Tao S (2016) Coal seam porosity and fracture heterogeneity of macro lithotypes in the Hancheng Block, eastern margin, Ordos Basin, China. Int J Coal Geol 159:18-29

Zhao J, Chen S, Zuo R, Carranza EJM (2011) Mapping complexity of spatial distribution of faults using fractal and multifractal models: vectoring towards exploration targets. Comput Geosci 37:1958-1966

Zhao Y, Lin B, Liu T, Zheng Y, Sun Y, Zhang G, Li Q (2021) Multifractal analysis of coal pore structure based on NMR experiment: a new method for predicting $T_{2}$ cutoff value. Fuel 283:119338

Zheng S, Yao Y, Liu D, Cai Y, Liu Y, Li X (2019) Nuclear magnetic resonance $T_{2}$ cutoffs of coals: a novel method by multifractal analysis theory. Fuel 241:715-724

Publisher's Note Springer Nature remains neutral with regard to jurisdictional claims in published maps and institutional affiliations. 